\title{
Biến đổi khí hậu và phát triển nghành năng lượng tái tạo ở Việt Nam
}

\author{
Nguyễn Thị Mỹ Hiền ${ }^{a}$, Hà Thị Hồng Hạnh ${ }^{b}$ \\ a Đại học Kinh tế Quốc Dân Hà Nội \\ b Đại học Kinh tế, Đại học Quốc gia Hà Nội
}

Ngày 14 tháng 1 năm 2022

Preprint DOI: https://osf.io/4cf79/

"Biến đổi khí hậu" một thuật ngữ không còn quá xa lạ với bất kì người dân nào trên toàn thế giới, bởi tính cấp thiết và nghiêm trọng của nó không chỉ riêng lẻ của mỗi quốc gia mà nó là vấn đề toàn cầu, là thách thức của toàn nhân loại (Q.-H. Vuong, 2021). Do đó, cần sự chung tay của tất cả các quốc gia trên thế giới để ứng phó biến đổi khí hậu, bảo vệ tương lai của sự sống trên hình tinh này. Rất nhiều những hội nghị tầm cỡ toàn cầu cũng như khu vực đã được tổ chức để bàn bạc và cùng đưa ra những hướng giải quyết cho vấn đề này. Trong đó, nổi bật nhất Hội nghị thượng đỉnh về biến đổi khí hậu COP26 vừa diễn ra vào ngày 31 tháng 10 đến 13 tháng 11 năm 2021 tại Vương Quốc Anh. Lần đầu tiên trong lịch sử 197 nước tham gia Công ước khung của Liên Hợp Quốc về biến đổi khí hậu đã đồng thuận cam kết "tăng tốc các nỗ lực hướng tới giảm thiểu điện than và loại bỏ trợ cấp dành cho nhiên liệu hóa thạch có hiệu suất thấp"(BBC News, 2021).

Là một quốc gia đang phát triển nhưng lại là nước chịu ảnh hưởng nặng nề của biến đổi khí hậu. Nhưng Việt Nam vẫn đang nỗ lực chung tay cùng thế giới đối mặt với biến đổi khí hậu. Tại COP26, Thủ tướng Chính phủ Đỗ Minh Chính đã đại diện Việt Nam đưa ra những cam kết cũng như một số hành động hiệu quả và mang tính xây dựng trong chiến dịch chống biến đổi khí hậu toàn cầu (Q. V. Khuc, 2022). Nổi bật, cam kết giảm phát thải ròng về 0 vào năm 2050 , giảm $30 \%$ lượng phát thải khí metan gây hiệu ứng nhà kính vào năm 2030. Với cam kết mạnh mẽ này đã thể hiện được quyết tâm chính trị cao của việt Nam cùng chung tay với cộng đồng quốc tế ứng phó với biến đối khí hậu (Tiep, 2022). 


\section{Tác động của biến đổi khí hậu đến ngàng năng lượng.}

Biến đổi khí hậu ngày càng tác động rõ nét đến đời sống con người, kinh tế và xã hội. Những năm trở lại đây, những hiện tượng thời tiết, khí hậu cực đoan, trong đó bão, lũ lụt, hạn hán kéo dài và thường xuyên gây thiệt hại nhiều tới tài nguyên, kinh tế và phát triển xã hội. Theo Cơ quan chiến lược về giảm nhẹ thiên tai của Liên Hợp Quốc (UNISDR), trong giai đoạn 19982017 kinh tế thế giới chịu thiệt hại 2250 tỷ đô la Mỹ, cao hơn $250 \%$ so với 20 năm trước đó (Ha Linh, 2020). Với xu thế biến đổi khí hậu như hiện tại nếu không quyết liệt thực hiện các giải pháp ứng phó biến đổi khí hậu, thiệt hại cho nền kinh tế đến năm 2050 trên toàn thế giới do biến đổi khí hậu sẽ là 7900 triệu đô la Mỹ và 3\% GDP trên toàn cầu (Tran Hong Thai, 2020).

Biến đổi khí hậu, ngoài việc gây ra những tác động tiêu cực trên, còn đe dọa đến anh ninh năng lượng. Đây là vấn đề được nhiều quốc gia trên thế giới, trong đó có Việt Nam hết sức quan tâm. Biến đổi khí hậu tại Việt Nam sẽ càng làm gia tăng hơn nữa mức độ phụ thuộc năng lượng. Nhất là sự mất ổn định về các nguồn cung năng lượng truyền thống sẽ tác động lớn đến việc bảo đảm an ninh năng lượng của quốc gia. Ngược lại, việc sử dụng nguồn năng lượng truyền thống lại là nguyên nhân chính gây ra hiệu ứng khí nhà kính. Do đó, việc nghiên cứu, đánh giá tác động qua lại giữa Biến đổi khí hậu với ngành năng lượng để định hình cụ thể một chiến lược an ninh năng lượng cho Việt Nam trong bối cảnh BĐKH.

\section{Phát triển ngành năng lượng tái tạo}

IPCC đã xác nhận rằng khí hậu của Trái đất đang thay đổi do hoạt động của con người, đặc biệt là từ việc sử dụng năng lượng hóa thạch. Và việc sử dụng năng lượng khá cao như hiện nay thì Việt Nam cần có những giải pháp hữu hiệu để ứng phó với tình trạng cạn kiệt năng lượng ảnh hưởng xấu đến khí hậu và môi trường. Tại $\mathrm{COP} 26$, đã đề cập đến 7 sáng kiến nhằm giảm thiểu biến đổi khí hậu, trong đó có đề cập đến đầu tư mạnh cho năng lượng sạch (Hoai Thanh, 2021). Cho đến thời điểm hiện tại, nhiều quốc gia đã chuyển dần những nguồn năng lượng truyền thống sang năng lượng mới và tái tạo. Đây là xu hướng chung để giải quyết vấn đề phát triển năng lượng bền vững, giảm thiểu ảnh hưởng tiêu cực của Biến đổi khí hậu.

Nhu cầu năng lượng ngày càng tăng và nhiên liệu hóa thạch đang cạn kiệt cho phép sự phát triển mạnh mẽ của năng lượng tái tạo. Năng lượng tái tạo có tầm quan trọng để phát triển bền vững, đa dạng hóa nguồn cung năng lượng và bảo vệ môi trường. Việc phát triển và sử dụng năng lượng tái tạo cần được ưu tiên cao, đặc biệt trong bối cảnh nâng cao nhận thức về các tác 
động bất lợi đến môi trường của việc sử dụng năng lượng hóa thạch. Bên cạnh đó sử dụng năng lượng tái tạo ít gây ra những tác động đến môi trường hơn là các nguồn năng lượng khác. Sự đa dạng của các nguồn năng lượng tái tạo cung cấp một loạt các lựa chọn linh hoạt để sử dụng chúng. Đặc biết nếu được sử dụng cẩn thận, ứng dụng thích hợp, năng lượng tái tạo có thể cung cấp nguồn năng lượng bền vững.

Do vậy, đối với Việt Nam, việc phát triển năng lượng tái tạo vừa là tiềm năng lớn cho nền kinh tế vừa giảm phát thải khí nhà kính, bảo vệ môi trường. Tuy nhiên, một thách thức lớn đối với năng lượng tái tạo là làm thể nào để đưa chúng tiếp cận gần hơn với mọi người, hơn hết đưa sản phẩm năng lượng tái tạo vào một thị trường đáng tin cậy với mức giá cạnh tranh với năng lượng có nguồn gốc từ nhiên liệu hóa thạch, mà không làm ảnh hưởng đến nền kinh tế. Vì việc sử dụng năng lượng tái tạo về bản chất sẽ phản ánh, hoặc được định hình từ văn hóa môi trường (Q. Van Khuc, 2021; Q. H. Vuong, 2021) bao gồm nhận thức, nhận thức về nhu cầu, về lối sống. Do đó, nên phát triển các chương trình trao đổi thông tin, đầu tư khoa học giáo dục và đào tạo để giúp tiếp cận gần hơn với năng lượng tái tạo (Q. H. Vuong, 2018). Cần tăng cường kiến thức về công nghệ năng lượng tái tạo bằng cách thiết lập các chương trình giáo dục và đào tạo. Các dự án nghiên cứu, phát triển năng lượng cần được khuyến khích để cải thiện thông tin và nâng cao nhận thức của cộng đồng. Quá trình chuyển giao và phát triển công nghệ cần được thể chế hóa thông qua trao đổi và kết nối quốc tế.

\section{Tài liệu tham khảo}

BBC News. (2021). COP 26: 197 nước đạt Thỏa thuận Khí hậu Glasgow nhò " thỏa hiệp ngôn tù" về than.

Ha Linh. (2020). Biến đổi khí hậu khiến bão, lũ ngày càng cực đoan. Kinh Tế Môi Trường, 1-7.

Hoai Thanh. (2021). 7 nỗ lực chống biến đổi khí hậu nổi bật trước thềm Hội nghị COP26. Báo Tin Tức, 1-5.

Khuc, Q. V. (2022). Về khả năng ứng dụng của hệ xử lý thông tin $3 \mathrm{D}$ và nguyên lý bán dẫn giá trị trong tìm kiếm giải pháp cho vấn đề ô nhiễm môi trường và biến đổi khí hậu ở Việt Nam. Tạp Chí Kinh Tế và Dự Báo, 1-5.

Khuc, Q. Van. (2021). Environmental culture thoughts to make a better world for our nature and children. OSF Preprints. https://doi.org/10.31219/osf.io/g5zex

Tiep, P. (2022). Thực hiện cam kết của Việt Nam tại COP26 : Thủ tướng 
gợi mở 8 nội dung. VietnamPlus, 1-3.

Tran Hong Thai. (2020). Đánh giá tác động của cực đoan khí hậu dưới ảnh hưởng biến đổi khí hậu với phát triển bền vững. Hội Đồng Lý Luận Trung Uong, 1-7.

Vuong, Q.-H. (2021). Western monopoly of climate science is creating an eco-deficit culture. Economy, Land \& Climate Insight, 11, 1-9. https://elc-insight.org/western-monopoly-of-climat

Vuong, Q. H. (2018). The (ir)rational consideration of the cost of science in transition economies. Nature Human Behaviour, 2(1), 5. https://doi.org/10.1038/s41562-017-0281-4

Vuong, Q. H. (2021). The semiconducting principle of monetary and environmental values exchange. Economics and Business Letters, 10(3), 284-290. https://doi.org/10.17811/ebl.10.3.2021.284-290 